\title{
Die Behandlung der dépeçage im europäischen Internationalen Privatrecht
}

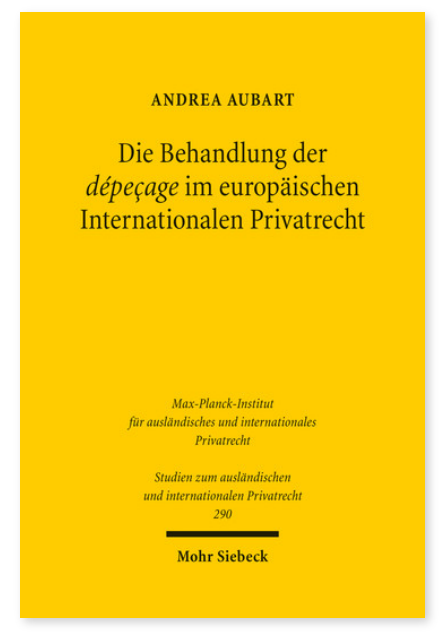

2013. XXVII, 248 Seiten. StudIPR 290

SBN 978-3-16-152694-7

DOI 10.1628/978-3-16-152694-7

eBook PDF $74,00 €$

ISBN 978-3-16-152666-4

fadengeheftete Broschur 74,00€
Der Begriff der dépeçage beschreibt im IPR eine Spaltung des anwendbaren Rechts. Im europäischen Rechtsraum ist die Skepsis gegenüber der dépeçage groß, während sie im US-amerikanischen Recht eine liberalere Handhabung erfährt. Dennoch können auch in der EU durch eine Spaltung des anwendbaren Rechts durchaus angemessene und im Vergleich zur Anwendung eines einheitlichen Rechts vorteilhafte Ergebnisse entstehen. Andrea Aubart untersucht die Behandlung der dépeçage schwerpunktmäßig in der Rom I-VO und der Rom II-VO. Darüber hinaus geht sie auf die neueren und geplanten EUVerordnungen zur Vereinheitlichung des IPR im Familien- und Erbrecht sowie auf die Übernahmerichtlinie ein. Dabei zeigt die Autorin die Voraussetzungen sowie die Folgen der dépeçage und ihre möglichen Anwendungsfelder auf.

Andrea Aubart Geboren 1985; Studium der Rechtswissenschaft in Trier; WS 2007/08: Studium an der University of East London; 2010-12 wissenschaftliche Mitarbeiterin am Lehrstuhl für Zivilrecht, insbesondere Internationales Privatrecht und Rechtsvergleichung der Universität Trier; seit November 2012 Rechtsreferendarin am Landgericht Trier.
Jetzt bestellen:

https://mohrsiebeck.com/buch/die-behandlung-der-depecage-im-europaeischen-internationalen-privatrecht-

9783161526947?no_cache=1

order@mohrsiebeck.com

Telefon: +49 (0)7071-923-17

Telefax: $+49(0) 7071-51104$ 